\title{
Removal of Heavy Metals from Polluted Solutions Using Kiwi Shell
}

\author{
R. Galeshi
}

\begin{abstract}
The aim of the present study was examination the ability of different contents of kiwi shell to adsorb different types (cadmium, nickel and lead) and concentrations $(5,10,20$, $30,40,50$ and $100 \mathrm{mgl}-1$ ) of heavy metal ions from aqueous solutions. The kiwi shell samples were collected from gardens of northern Iran, washed and grounded to assess the monometal and competitive adsorption behavior of $\mathrm{Cd}, \mathrm{Ni}$ and $\mathrm{Pb}$ on the kiwi shell. The sum of adsorbed heavy metals on the kiwi shell could well described using both the Freundlich (R2 between $0.92-0.98)$ and Langmuir (R2 between $0.96-0.99)$ equations. All of the sorption isotherms were of the L-curve type. Results from the batch experiments show that the maximum adsorption capacities of the metals by the kiwi shell were in the order of $\mathrm{Pb}>\mathrm{Ni}>\mathrm{Cd}$ based on the both monometal and competitive systems. The distribution coefficient (kd), Freundlich capacity coefficient (kF) and Langmuir maximum capacity (a) were higher in monometal than in competitive system. Competition significantly reduced metals $\mathrm{k} \square$, especially for $\mathrm{Cd}$ and $\mathrm{Ni}$. The sorption capacity in different contents of kiwi shell was in the order of $5>3>1 \mathrm{~g}$ for the metals. The total sorption amount increased with the increasing the initial concentration of the metal; however, distribution coefficient values for each metal concentration at both systems indicated that the kiwi shell capacities for sorption decreased with increasing the initial concentration of the metals.
\end{abstract}

Index Terms-Kiwi shell, sorption of heavy metals.

\section{INTRODUCTION}

Heavy metals are naturally occurring elements that have a high atomic weight and a density at least 5 times greater than that of water. These metals are toxic pollutants that released into the environment as a result of different activities such as industrial, mining, and agricultural activities [1]. Disposal of industrial, agricultural and urban effluents has led to a significant increase in metal contamination of water systems [2]-[4]. As a result of this problem, the need to remove and recovery these heavy metals from polluted water resources have been on the increase. It has been applied various processes to eliminate the metals from water and wastewater such as chemical precipitation, electrochemical reduction, ion-exchange, reverse osmosis, solvent extraction and evaporation, etc. [5]. However, these processes have not been used extensively because of their high cost. Hence, more economical techniques such as adsorption and the use of low-cost sorbents for removal of toxic metals from wastewater has been a focus [5]. Therefore, there is a need to search an effective low cost adsorbent for economical wastewater treatment. In recent years, low-cost adsorbents

Manuscript received June 24, 2016; revised September 6, 2016.

R. Galeshi. is with the Corporation of Mehravijhe, Iran (e-mail: ramingaleshi1981@gmail.com). are widely used to remove heavy metals from waters. Adsorbents, such as sawdust [6], tourmaline [7], rice husk [8], chitosan [9], manure compost [10], charcoal [11], lawny grass [12], activated carbon [13], tea waste [14] and pistachio hull biomass [15], have been successfully applied for physical removal of heavy metals. Agricultural residues contain lignin and cellulose, which usually constitute the main structure of it. There are compounds such as hemi-cellulose, lipids, proteins, glucose, starch, water, hydrocarbons and other compounds in their structure, also. These groups have the ability to link with heavy metals in solution by replacing hydrogen ions or giving pair of electrons of these groups to form complexes with metal ions.

Kiwi is one of the most important horticultural products in northern Iran. Kiwi shell is considered as one of relevant natural absorbent, because it is disregarded after use [16]. The aim of the present study is examination the potential of kiwi shells to adsorb heavy metal ions from aqueous solutions. The effect of adsorbent doses, metal concentrations and metal type on the removal of heavy metal ions was studied and the adsorption isotherms and probable mechanism were explained, also.

\section{MATERIAL AND METHODS}

Kiwi shells obtained from gardens of northern Iran were washed several times by distilled water to remove all dirt particles. The washing process was continued by $0.1 \mathrm{M}$ nitric acid and distilled water till the wash water contained no color. The washed shells were then ground, using a ball mill, sieved through 40 mesh size, poured into polyethylene tubes and exposed by solution of $0.5 \mathrm{M} \mathrm{CaCl} 2$ at $150 \mathrm{rpm}$ on a shaker to saturate the surface of sorbent by calcium and remove all of the exchangeable cations on the surface of kiwi shell. Then the kiwi shell was exposed by solution of $0.01 \mathrm{M} \mathrm{NaOH}$ for $30 \mathrm{~min}$ on a shaker at $150 \mathrm{rpm}$, centrifuged for $15 \mathrm{~min}$ at 3000 $\mathrm{rpm}$ and dried in oven at $105{ }^{\circ} \mathrm{C}$ for $24 \mathrm{~h}$.

$1 \mathrm{~g}$ from dried kiwi shell sample was weighed and poured into acid-washed polyethylene tubes and $20 \mathrm{ml}$ of the stock solution of $\mathrm{CdCl}_{2}, \mathrm{PbCl}_{2}$ and $\mathrm{NiCl}_{2}$ at the concentrations of 5 , $10,20,30,40,50$ and $100 \mathrm{mgl}^{-1}$ added to the tubes, individually. The tubes were shaken at $150 \mathrm{rpm}$ for $24 \mathrm{~h}$, as the equilibrium time, at $25{ }^{\circ} \mathrm{C}$. The kiwi shell samples dissolved in metal solutions $(1: 10 \mathrm{w} / \mathrm{v})$ were centrifuged initially at $3000 \mathrm{rpm}$ for $15 \mathrm{~min}$ to remove sediment. Then, the supernatant was filtered through filter paper (Wathman filters No.42). $\mathrm{Cd}, \mathrm{Pb}$ and $\mathrm{Ni}$ concentrations in the supernatants were measured by atomic adsorption spectrophotometer.

Competitive adsorption isotherms were performed in the same way, but by adding $\mathrm{Cd}, \mathrm{Pb}$ and $\mathrm{Ni}$ at a 1:1:1 ratio.

Monometal and competitive adsorption experiments had 
conducted in constant $\mathrm{pH}$ (7-7.5). The control of $\mathrm{pH}$ was done by acid or base solutions and both mono- and multimetal experiments were carried out in a background electrolyte of $0.01 \mathrm{M} \mathrm{CaCl}_{2}$ and were replicated three times. The presented results are the means of the three determinations.

The amount of sorbed metals by kiwi shell was calculated with the equation:

$$
q=\frac{\left(C_{O}-C_{e}\right) V}{M}
$$

where $q$ is the amount of adsorbed metal $\left(\mathrm{mg} \mathrm{kg}^{-1}\right), C_{o}$ is the initial concentration of the metal in solution $\left(\mathrm{mg} \mathrm{l}^{-1}\right), C_{e}$ is the equilibrium concentration of the metal in solution $\left(\mathrm{mg} \mathrm{l}^{-1}\right), V$ is the solution volume $(\mathrm{ml})$, and $M$ is the weight of dried sorbent $(\mathrm{kg})$.

The distribution coefficient $\left(K_{d}\right)$, was calculated according to the following formula:

$$
\begin{gathered}
K_{d}= \\
\text { Equilibrium metal concentration adsorbed } \\
\hline \text { Equilibrium metal concentration in solution }
\end{gathered}
$$

The distribution coefficients for each metal concentration for the studied sorbent were calculated. An average $K_{d}$ value $\left(\mathrm{K}_{\text {dmedium }}\right)$ for each metal in the studied sorbent, which calculated based on formula:

$$
\frac{K_{\text {dmedium }}=}{\frac{\mathrm{K}_{\mathrm{d} 5}+\mathrm{K}_{\mathrm{d} 10}+\mathrm{K}_{\mathrm{d} 20}+\mathrm{K}_{\mathrm{d} 30}+\mathrm{K}_{\mathrm{d} 40}+\mathrm{K}_{\mathrm{d} 50}+\mathrm{K}_{\mathrm{d} 100}}{7}}
$$

was used to comparing the adsorption capacities of different contents of kiwi shell for the metals.

Adsorption data were fitted to the following Freundlich and Langmuir equations.

The Freundlich equation can be expressed as:

$$
q=k_{F} C^{\frac{1}{n}}
$$

where $q$ (or $\mathrm{x} / \mathrm{m})$ and $C$ (equilibrium concentration) were defined earlier, $k_{F}$ and $n$ are Freundlich constants related to adsorption capacity and adsorption intensity, respectively. The linear form of the Freundlich isotherm is given by:

$$
\log q=\log k_{F}+\frac{1}{n} \log C
$$

Freundlich parameters can be obtained by plotting $\log q$ vs. $\log C$, with $\frac{1}{n}$ being the slope and $\log k_{F}$ being the intercept of the line.

The Langmuir adsorption equation can be expressed as:

$$
q=\frac{a_{m} b C}{(1+b C)}
$$

where $q$ and $C$ were defined previously, $a_{m}$ is the maximum amount of adsorptive that can be adsorbed (monolayer capacity) and $b$ is a constant related to the binding strength. The linear form of Langmuir isotherm equation is represented by:

$$
\frac{1}{q}=\frac{1}{a_{m} b C}+\frac{1}{a}
$$

Plotting $\frac{1}{q}$ vs $\frac{1}{C}$, a straight line with slope $\frac{1}{a_{m} b}$ and intercept $\frac{1}{a_{m}}$ is obtained. The Langmuir parameters, $a_{m}$ and $b$, are calculated from the slope and intercept of the graphs.

All of the above experiments were conducted at sorbent contents of 3 and $5 \mathrm{~g}$, also and the presented results are the means of the three determinations.

\section{RESULTS AND DISCUSSION}

Fig. 1 and Fig. 2 illustrate the monometal and competitive adsorption isotherms, respectively for the studied metals by three contents of kiwi shell. On the $y$-axis, $q$ represents the metal concentration sorbed onto kiwi shell and on the $x$-axis, $C$ represents metal equilibrium concentration in solution. As can be seen at Fig. 1 and 2, adsorption isotherms for the studied metals by the sorbent exhibited significant differences in shape and in the amount adsorbed.

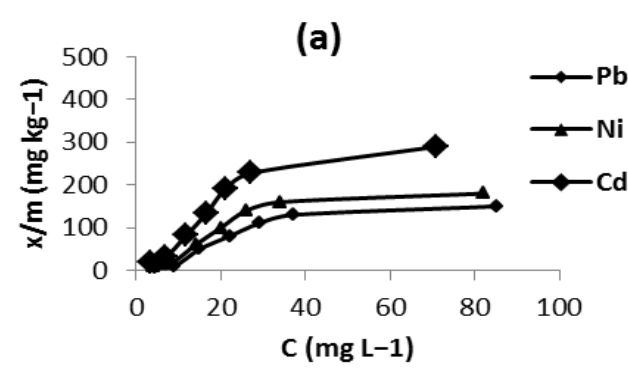

(b)
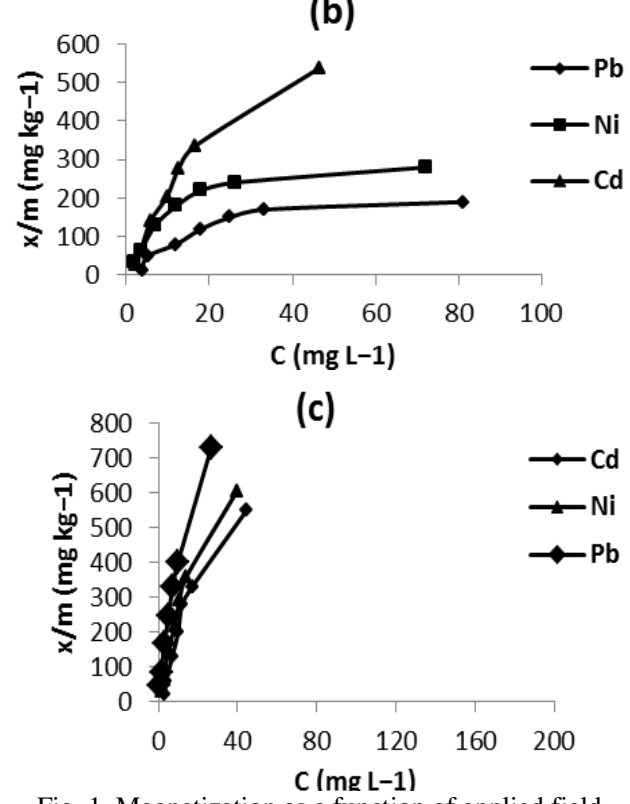

Fig. 1. Magnetization as a function of applied field.

The characteristic steeper slope of the $\mathrm{Pb}$ adsorption isotherms in contrast to the slope of the $\mathrm{Cd}$ and $\mathrm{Ni}$ adsorption 
isotherms indicated a stronger affinity for $\mathrm{Pb}$ than $\mathrm{Cd}$ and $\mathrm{Ni}$. Although, the metals had steeper slope at monometal system compared to competitive system, the three metals behaved identically in combination as they did when added individually; so that the both monometal and competitive adsorption isotherms of the metals were of the L-curve type at all of the sorbent contents, which characterized by a decreasing slope as concentration increases since vacant adsorption sites decrease as the adsorbent becomes covered. Such adsorption behavior could be explained by the high affinity of the adsorbent for the adsorptive at low concentrations, which then decreases as concentration increases [17].

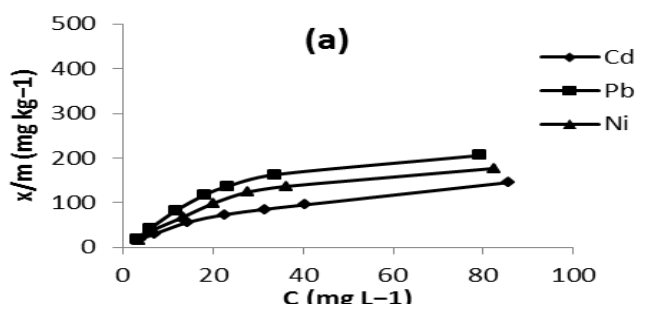

(b)

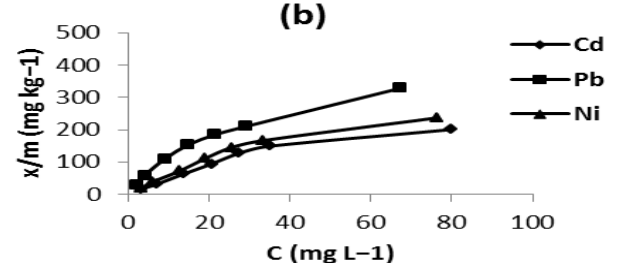

(c)

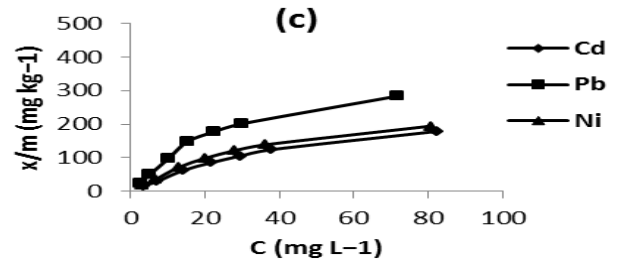

Fig. 2. Competitive adsorption isotherms of $\mathrm{Cd}, \mathrm{Pb}$, and $\mathrm{Ni} \mathrm{n}, \mathrm{Cd}$, and $\mathrm{Cu}$ in different contents of kiwi shell (a: 1, b: 3 and c: $5 \mathrm{~g}$ ).

The distribution coefficient, the slope of a simple linear model, is often used to characterize the mobility of trace metals in aquatic environments; low $\mathrm{K}_{\mathrm{d}}$ values imply that most metal remains in solution, and high $\mathrm{K}_{\mathrm{d}}$ values indicate that the metal has great affinity for the sorbent [18], [19].
Distribution coefficient in the different contents of kiwi shell was in the order of $5>3>1$ for all the metals.

The $\mathrm{K}_{\mathrm{d}}$ values of the metals in monometal and competitive systems (TABLE I) indicated that the order of reduced metal sorption was $\mathrm{Pb}>\mathrm{Ni}>\mathrm{Cd}$ in most of the cases.

Competition among the three metals reduced their $\mathrm{K}_{\mathrm{d}}$ values significantly in all contents of kiwi shell (TABLE I). Significant suppressive effects of competitive metals on the adsorption of a particular metal have also been reported by Antoniadis et al [20]. Although competition reduced sorption of all three metals, the magnitude of these effects was different for each metal. Cadmium $\mathrm{K}_{\mathrm{d} \mu}$ decreased by nearly $65 \%$ at contents of 1 gr due to competition, and by $61 \%$ at 2 gr and $64 \%$ at 5 gr. This compares to competition- induced reductions of around $51 \%, 50 \%$ and $47 \%$ for $\mathrm{Pb}$ at 1,3 and 5 gr, respectively, and $59 \%, 58 \%$ and $57 \%$ for $\mathrm{Ni}$ at 1,3 and 5 gr, respectively. This suggests that upon co-addition of the three metals to the kiwi shell, $\mathrm{Pb}$, and to a lesser extent $\mathrm{Ni}$, became preferentially adsorbed. It seems that preferential retention of $\mathrm{Pb}$ can be explained by the factors which are in favour of $\mathrm{Pb}$, namely, electronegativity and first hydrolysis constant. According to McBride [21], selective metal retention can be explained by differences in electronegativity which, in this case, is higher for $\mathrm{Pb}(2.0)$ than $\mathrm{Ni}$ (1.72) and Cd (1.69).

Also, $K_{d}$ values for each metal concentrations at both monometal and competitive systems indicated that $\mathrm{K}_{\mathrm{d}}$ decreased with increrasing applied concentration of the metal (TABLE I). On the other hand, the differences in $\mathrm{K}_{\mathrm{d}}$ of the metals were low at the lower equilibrium concentrations in the sorbents. Thus, at low metal concentrations, preferential adsorption was not strong for $\mathrm{Pb}, \mathrm{Ni}$ and $\mathrm{Cd}$.

The Freundlich $\left(k_{F}\right.$ and $\left.n\right)$ and Langmuir $\left(a_{m}\right.$ and $\left.b\right)$ constants for monometal and competitive systems were calculated and the values are given in TABLE II. All of the sorption isotherms were adequately described by both the Freundlich $\left(\mathrm{R}^{2}\right.$ between $\left.0.92-0.98\right)$ and Langmuir $\left(\mathrm{R}^{2}\right.$ between $0.96-0.99)$ equations with a high coefficient of determinations.

TABLE I: Distribution CoefFicients, Kd (L KG_1) For the MonOMETAL AND COMPETITIVE AdSORPTION OF CD, PB, AND Ni by DifFERENT CONTENTS OF KIWI SHELL IN THE DIFFERENT INITIAL CONCENTRATIONS

\begin{tabular}{|c|c|c|c|c|c|c|c|c|c|c|}
\hline & & & 5 & 10 & 20 & 30 & 40 & 50 & 100 & $\mathrm{~K}_{\mathrm{d} \mu}$ \\
\hline \multirow{5}{*}{$1 \mathrm{~g}$} & \multirow[b]{2}{*}{ Monometal } & $\mathrm{Cd}$ & 1.17 & 1.07 & 0.96 & 0.78 & 0.70 & 0.60 & 0.40 & 0.81 \\
\hline & & $\mathrm{Pb}$ & 1.36 & 1.33 & 1.21 & 1.29 & 1.18 & 1.01 & 0.55 & 1.13 \\
\hline & \multirow{3}{*}{ Competitive } & $\mathrm{Cd}$ & 0.30 & 0.39 & 0.36 & 0.30 & 0.25 & 0.22 & 0.16 & 0.28 \\
\hline & & $\mathrm{Pb}$ & 0.55 & 0.65 & 0.66 & 0.60 & 0.67 & 0.45 & 0.24 & 0.54 \\
\hline & & $\mathrm{Ni}$ & 0.40 & 0.55 & 0.47 & 0.46 & 0.41 & 0.35 & 0.20 & 0.41 \\
\hline \multirow{5}{*}{$3 \mathrm{~g}$} & \multirow[t]{2}{*}{ Monometal } & $\mathrm{Pb}$ & 2.75 & 2.31 & 2.05 & 1.91 & 1.89 & 1.37 & 1.15 & 1.92 \\
\hline & & $\mathrm{Ni}$ & 1.80 & 1.27 & 1.35 & 1.32 & 1.22 & 0.90 & 0.56 & 1.20 \\
\hline & \multirow{3}{*}{ Competitive } & $\mathrm{Cd}$ & 0.50 & 0.41 & 0.43 & 0.42 & 0.44 & 0.39 & 0.24 & 0.41 \\
\hline & & $\mathrm{Pb}$ & 1.21 & 1.35 & 1.14 & 0.97 & 0.80 & 0.68 & 0.46 & 0.94 \\
\hline & & $\mathrm{Ni}$ & 0.55 & 0.59 & 0.53 & 0.55 & 0.54 & 0.47 & 0.29 & 0.50 \\
\hline \multirow{5}{*}{$5 \mathrm{~g}$} & \multirow[b]{2}{*}{ Monometal } & $\mathrm{Cd}$ & 1.50 & 1.24 & 1.05 & 0.95 & 0.90 & 0.82 & 0.42 & 0.98 \\
\hline & & $\mathrm{Pb}$ & 2.59 & 1.71 & 1.42 & 1.35 & 1.22 & 1.05 & 0.58 & 1.42 \\
\hline & \multirow{3}{*}{ Competitive } & $\mathrm{Cd}$ & 0.43 & 0.39 & 0.41 & 0.37 & 0.33 & 0.31 & 0.20 & 0.35 \\
\hline & & $\mathrm{Pb}$ & 0.83 & 0.90 & 0.90 & 0.91 & 0.74 & 0.63 & 0.37 & 0.75 \\
\hline & & $\mathrm{Ni}$ & 0.52 & 0.48 & 0.52 & 0.46 & 0.40 & 0.36 & 0.23 & 0.42 \\
\hline
\end{tabular}




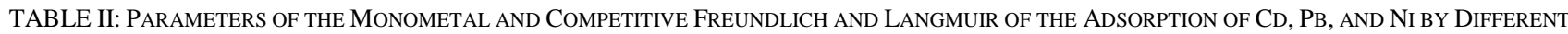
CONTENTS OF KIWI SHELL

\begin{tabular}{|c|c|c|c|c|c|c|}
\hline & & & \multicolumn{2}{|c|}{ Freundlich } & \multicolumn{2}{|c|}{ Langmuir } \\
\hline & & & $\mathrm{K}_{\mathrm{F}}$ & $\mathrm{n}$ & $\mathrm{A}$ & $\mathrm{b}$ \\
\hline \multirow{6}{*}{$1 \mathrm{~g}$} & \multirow{3}{*}{ Monometal } & $\mathrm{Cd}$ & 16.52 & 1.40 & 12.13 & 0.03 \\
\hline & & $\mathrm{Pb}$ & 18.70 & 1.26 & 13.66 & 0.02 \\
\hline & & $\mathrm{Ni}$ & 16.94 & 1.28 & 12.19 & 0.02 \\
\hline & \multirow{3}{*}{ Competitive } & $\mathrm{Cd}$ & 7.66 & 1.46 & 4.89 & 0.03 \\
\hline & & $\mathrm{Pb}$ & 9.50 & 1.27 & 5.61 & 0.00 \\
\hline & & $\mathrm{Ni}$ & 7.20 & 1.24 & 4.19 & 0.00 \\
\hline \multirow{6}{*}{$3 \mathrm{~g}$} & \multirow{3}{*}{ Monometal } & $\mathrm{Cd}$ & 20.98 & 1.46 & 17.33 & 0.05 \\
\hline & & $\mathrm{Pb}$ & 31.55 & 1.36 & 28.26 & 0.06 \\
\hline & & $\mathrm{Ni}$ & 21.78 & 1.36 & 18.27 & 0.05 \\
\hline & \multirow{3}{*}{ Competitive } & $\mathrm{Cd}$ & 6.32 & 1.17 & 4.89 & 0.01 \\
\hline & & $\mathrm{Pb}$ & 18.15 & 1.38 & 12.78 & 0.02 \\
\hline & & $\mathrm{Ni}$ & 7.78 & 1.17 & 5.57 & 0.00 \\
\hline \multirow{6}{*}{$5 \mathrm{~g}$} & \multirow{3}{*}{ Monometal } & $\mathrm{Cd}$ & 18.47 & 1.43 & 15.58 & 0.04 \\
\hline & & $\mathrm{Pb}$ & 28.54 & 1.49 & 27.16 & 0.09 \\
\hline & & $\mathrm{Ni}$ & 17.22 & 1.29 & 13.01 & 0.02 \\
\hline & \multirow{3}{*}{ Competitive } & $\mathrm{Cd}$ & 6.04 & 1.22 & 4.37 & 0.01 \\
\hline & & $\mathrm{Pb}$ & 12.79 & 1.25 & 8.33 & 0.00 \\
\hline & & $\mathrm{Ni}$ & 7.66 & 1.26 & 5.17 & 0.01 \\
\hline
\end{tabular}

The adsorption capacities $\left(k_{F}\right)$ and the maximum adsorption capacities $\left(a_{m}\right)$ for the metals determined by the Freundlich and Langmuir isotherms, respectively were in the order of $\mathrm{Pb}>\mathrm{Ni}>\mathrm{Cd}$ in the both monometal and multimetal conditions. The adsorption capacity and the maximum adsorption capacity of the metals in the multimetal condition were lower than the monometal condition. Generally, $k_{F}$ and $a_{m}$ values of both mono- and multimetal systems indicate that the sorption value of the metals by sorbent contents of 3 and 5 gr was higher than that of 1 gr. However, difference between adsorption capacity of $\mathrm{Pb}$ and $\mathrm{Cd}\left(k_{F, P b}-k_{F, C d}\right)$ or between $\mathrm{Cu}$ and $\mathrm{Zn}\left(k_{F, P b}-k_{F, N i}\right)$ at sorbent contents of $1 \mathrm{~g}$ is lower than the difference at 3 and $5 \mathrm{~g}$. On the other hand, as can be seen in TABLE II, Langmuir binding strength for competitive system is more than monometal system for all the studied metals. In short, $b$ reflects the retention intensity and the number of sites available for a sorbate. Higher $b$ values have been related to specifically sorbed metals at high energy surfaces with low dissociation constants. Alternatively, lower $b$ values appear to be releated to sorption at low energy surfaces with high dissociation constants [21]. The multimetal isotherm $b$ values in the sorbent may indicate that competition promotes the retention of the three metals on more specific sorption positions. As a result, although the maximum adsorption capacity $\left(a_{m}\right)$ decreases for $\mathrm{Cd}, \mathrm{Pb}$ and $\mathrm{Ni}$, the metals are held more strongly. Generally, $\mathrm{Ni}$ and $\mathrm{Cd}$ retention is more dependent on electrostatic interactions with solid phase exchange sites. In contrast $\mathrm{Pb}$ retention is less dependent on this type of adsorption and more dependent on covalent interactions with the functional groups on the sorbent surface [21].

\section{CONCLUSION}

In the present study the monometal and competitive adsorption behavior of $\mathrm{Cd}, \mathrm{Pb}$ and $\mathrm{Ni}$ onto different contents of three contents of kiwi shell was investigated.

Based on the data presented in this study, we conclude as follows:

1) Kiwi shell has a considerable capacity to the heavy metal adsorption in the polluted solutions.

2) Kiwi shell has a stronger affinity for $\mathrm{Pb}$ than $\mathrm{Ni}$ and $\mathrm{Cd}$ when introduced to the polluted solution individually or at the same time. This implies, when a water resource is rich in $\mathrm{Cd}, \mathrm{Ni}$ and $\mathrm{Pb}$, there is greater potential for toxicity of $\mathrm{Cd}$ and $\mathrm{Ni}$ than $\mathrm{Pb}$, by their higher mobility and lower adsorption.

3) The presence of other cations decreases the sorption of all metals by kiwi shell; however the magnitude of these effects is different for each metal. Co-addition of the $\mathrm{Cd}$, $\mathrm{Pb}$ and $\mathrm{Ni}$ to the solution, $\mathrm{Pb}$, and to a lesser extent $\mathrm{Ni}$ became preferentially adsorbed.

4) The kiwi shell performance for adsorption of heavy metals is strongly affected by heavy metals initial concentration and content of sorbent. In addition, the sorption content of heavy metals by kiwi shell increase with the initial concentration of heavy metals, however the $\mathrm{K}_{\mathrm{d}}$ decrease with increrasing applied concentrations of the metal.

\section{REFERENCES}

[1] A. Esposito, F. Pagnanelli, F. Beolchini, V. Dovi, and F. Veglio, "Cadmium and copper biosorption on Sphaerotilus natans: Influence of $\mathrm{pH}$ and biomass concentration on the biosorption modeling," Journal of Hydrometallurgy, vol. 60, pp. 129-141, 2001.

[2] U. Förstner and G. T. W. Wittmann, Metal Pollution in the Aquatic Environment, Springer Verlag, New York, 1981.

[3] A. Tessier and P. Campbell, "Partitioning of trace metals in sediments. In: Kramer, J R, Allen H. E. (Eds.), Metal Speciation: Theory, analysis and application," Lewis Publs, Chelsea, MI, U.S.A., pp. 183-199, 1988.

[4] M. Jayaprakash, S. Srinivasalu, M. P. Jonathan, and V. Ram-Mohan, "A baseline study of physico-chemical parameters and trace metals in waters of Ennore creek, Chennai, India," Journal of Marine Pollution Bulletine, vol. 50, pp. 583-589, 2005.

[5] H. Demiral, I. Demiral, F. Tumsek, and B. Karabacakoglu, "Adsorption of chromium (VI) from aqueous solution by activated carbon derived from olive bagasse and applicability of different adsorption models," Chem. Eng. J., 144, 188-196, 2008.

[6] A. Ahmad, M. Rafatullah, O. Sulaiman, M. Hakimi Ibrahim, Y. Chii, and B. M. Siddique, "Removal of $\mathrm{Cu}$ (II) and $\mathrm{Pb}$ (II) ions from aqueous solutions by adsorption on sawdust of Meranti wood," Desalination, vol. 247, pp. 636-646, 2009.

[7] H. Liu, C. Wang, J. Liu, B. Wang, and H. Sun, "Competitive adsorption of $\mathrm{Cd}$ (II), $\mathrm{Zn}$ (II) and $\mathrm{Ni}$ (II) from their binary and ternary acidic systems using tourmaline," J. Environ. Manage., vol. 128, pp. 727-734, 2013.

[8] E. I. El-Shafey, "Removal of $\mathrm{Zn}$ (II) and $\mathrm{Hg}$ (II) from aqueous solution on a carbonaceous sorbent chemically prepared from rice husk," $J$. Hazard. Mater., vol. 175, pp. 319-327, 2010. 
[9] Y. Zhu, J. Hu, and J. Wang, "Competitive adsorption of Pb (II), Cu (II) and $\mathrm{Zn}$ (II) onto Xanthate-modified magnetic chitosan," J. Hazard. Mater., pp. 221-222, 155-161, 2012.

[10] M. Zhang, "Adsorption study of $\mathrm{Pb}$ (II), $\mathrm{Cu}$ (II) and $\mathrm{Zn}$ (II) from simulated acid mine drainage using dairy manure compost," Chem. Eng. J., vol. 172, pp. 361-368, 2011.

[11] F. Yuan Wang, H. Wang, and J. Weima, "Cloud point extraction combined with high-performance liquid chromatography for speciation of chromium (III) and chromium (VI) in environmental sediment samples," J. Hazard. Mater., vol. 177, pp. 114-118, 2010.

[12] L. D. Lü, Lu, L. Chen, and F. Luo, "Removal of Cd (II) by modified lawny grass cellulose adsorbent," Desalination, vol. 259, pp. 120-130, 2010.

[13] F. Sabermahani., M. Khajehsadegh, and N. Madadi Mahani, "Removal of chromium (VI) ions from aqueous solutions by using Kiwi shell," Science Journal (CSJ), vol. 36, no. 3, pp. 2083-2089, 2015.

[14] M. K. Mondal, "Removal of Pb (II) from aqueous solution using activated tea waste: Adsorption on a fixed-bed column," J. Environ. Manage., vol. 90, no. 32, pp. 3266-3271, 2009.

[15] G. Moussavi and B. Barikbin, "Biosorption of chromium (VI) from industrial wastewater onto pistachio hull waste biomass," Chem. Eng. J., vol. 162, pp. 893-900, 2010.

[16] B. Lorestani, C. Arjangi, and H. Merrikhpour, "Effect of kiwi shell and incubation time on mobility of lead and cadmium in contaminated clay soil," Journal of Chemical Health Risks, vol. 4, no. 2, pp. 23-37, 2014.

[17] D. L. Sparks, Environmental Soil Chemistry, Academic Press, San Diago, 1995.
[18] T. H. Christensen, "Cadmium soil sorption at low concentrations: VIII. Correlation with soil parameters," Journal of Water, Air and Soil Pollution, vol. 44, pp. 71-82, 1989.

[19] D. C. Seo, K. Yu, and R. D. Deluane "Comparison of monometal and multimetal adsorption in Mississippi River alluvial wetland sediment: Batch and column experiments," Chemosphere, vol. 73, pp 1757-1764, 2008

[20] M. B. McBride, Environmental Chemistry of Soils, Oxford Univ Press, New York, 1994.

[21] V. Antoniadis, C. D. Tsadilas, and D. J. Ashworth, "Monometal and competitive adsorption of heavy metals by sewage sludgeamended soil," Chemosphere, vol. 68, pp. 489-494, 2007.

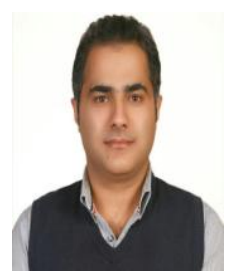

Ramin Galeshi was born in Karaj, Iran, in 1981. He received the B.E. degree in civil engineering from the Islamic Azad University of Shahrood, Iran, in 2007. In 2007, he joined the Iranian Corporation of Mehravijhe, as a project manager, and in 2013 became as responsible for research and development in Kia Sabz Ashian Koosha Corporation in presentation of agricultural and environmental advises. His current research interests include the environmental and economic effects of using the organic and chemical fertilizers in Iranian gardens and fields, investigation on recovery of agricultural wastes as fertilizer and other usages. Also, he was the recipient of an award at 2015 from the Agriculture Corporation Union of Ramsar and Tonekabon in Iran, as one of the best producers of kiwi and citrus. 